\title{
THE LINGUISTIC DETERMINATION OF CONSCIOUS THOUGHT CONTENTS
}

\author{
Agustín Vicente \\ Ikerbasque \& University of the Basque Country \\ Marta Jorba \\ University of the Basque Country
}

\begin{abstract}
In this paper we address the question of what determines the content of our conscious episodes of thinking, considering recent claims that phenomenal character individuates thought contents. We present one prominent way for defenders of phenomenal intentionality to develop that view and then examine 'sensory inner speech views', which provide an alternative way of accounting for thought-content determinacy. We argue that such views fare well with inner speech thinking but have problems accounting for unsymbolized thinking. Within this dialectic, we present an account of the nature of unsymbolized thinking that accords with and can be seen as a continuation of the activity of inner speech, while offering a way of explaining thought-content determinacy in terms of linguistic structures and representations.
\end{abstract}

\section{The indeterminacy problem: phenomenal intentionality vs. naturalistic programs}

In recent years, the phenomenal intentionality program has garnered interest within the philosophical debate surrounding intentionality. Phenomenal intentionality is intentionality that can be attributed to a mental state, purely in virtue of its phenomenal character (Kriegel, 2014: 2). Different views of how to describe and explain such intentionality stress, in one way or another, a close connection to (phenomenal) consciousness: the so-called 'inseparatism' claim (Horgan and Tienson, 2002). Such views offer a new perspective on the question of content determinacy, that is, on what it is that warrants a certain content of a mental state and not some other: phenomenal character plays this role in explaining intentionality. These views are typically contrasted with naturalistic approaches to intentionality which attempt to explain intentionality reductively through a relation that holds between the organism and the environment, by way of some kind of representational device. One major problem that 
naturalistic theories of content encounter is the so-called indeterminacy of content (see Neander, 2012 for an overview). This problem concerns the alleged result that naturalistic theories warrant more than one content attribution in cases where just one is correct $^{1}$.

In this paper we will be concerned with the determinacy of contents of occurrent episodes of thinking (e.g., judging that $p$, or entertaining that $q$ ), which are also the focus of much of the cognitive phenomenology debate. The problem that naturalistic theories allegedly face in this case is that they do not have the necessary tools to specify which content an individual's occurrent thought has: it seems that we cannot distinguish, on the basis of such theories, between thinking 'there is a red apple here', 'there is a red apple-shaped patch here', 'a red apple or a round red pear is in front of me', or 'there is something edible over there'. There are several issues involved here that we do not need to address in detail; the literature on how to address the obstinate problem of indeterminacy from a naturalistic viewpoint is huge and the approaches are varied. Here, we only wish to note a contrast between naturalist and phenomenalist approaches to intentionality: whereas most kinds of reductive naturalistic theories of intentionality have tended to set aside conscious intentionality as a derivative form of intentionality, the phenomenal intentionality program precisely gives phenomenal consciousness a preeminent role in explaining intentionality and thus content determinacy. In this way, we delineate our own proposal for a third, alternative way of accounting for thought—content determination.

This paper is thus devoted to the issue of what determines or individuates the

\footnotetext{
${ }^{1}$ A locus classicus of this debate concerning the contents of perception is the determination of a frog's visual contents (see, e.g., Loewer and Rey, 1991). Note that, although most of the examples discussed concern the contents of basic-level representations, naturalistic approaches also try to account for the contents of conceptual and propositional representations, usually by providing an account of Mentalese semantics (see again Loewer and Rey, 1991).
} 
contents of occurrent conscious episodes of thinking ${ }^{2}$. We start by presenting the motivations for the thesis that phenomenal character can provide the required thoughtcontent determinacy. Then we examine an alternative way of accounting for the determination of thought contents, the 'sensory inner speech view', which emerges from a certain way of thinking about self-knowledge. We argue that such a view fares well with linguistic thinking, but has problems accounting for 'unsymbolized thinking' (UT) (Hurlburt and Akhter, 2008), characterized as conscious thinking that involves no sensory or perceptual vehicle. Against this dialectic background, we present a view of the nature of UT that accords with and can be seen as a continuation of the activity of inner speech, and also offers a new way of explaining thought-content determinacy. Interestingly, the view we propose does not endorse the individuative claim, but is in harmony with one aspect of phenomenal intentionality views: the idea that determinacy is in some way connected to consciousness. This connection, in our account, is via linguistic capacity.

As we say, we will not dwell on the details of naturalistic approaches and throughout the paper we mention them only occasionally, always conditionally: what would happen if they worked, and what would happen if they did not. If the general problems naturalistic views encounter are not as acute as we assume, our account will be limited to explaining the determination of the contents of conscious episodes of thinking. However, if naturalistic views are as beleaguered as we believe them to be, what follows from the picture we present is that only conscious episodes of thinking have determinate contents. Moreover, even if naturalistic views could account in some way for a determinate content of unconscious episodes of thinking, we claim that such a

\footnotetext{
${ }^{2}$ We understand conscious episodes of thinking that $p$ as occurrent mental episodes having both a propositional content and an attitude component (judging, entertaining, doubting, assuming, etc.), and they should be distinguished from thoughts as standing states (beliefs, etc.) and as mere propositional contents.
} 
content is not identical to the content that related conscious episodes of thinking have (i.e., the truth conditions of the content of the unconscious episode differ from those of the conscious episode). If naturalistic views fail, our perspective entails that determinate truth-conditional contents are only to be found in episodes of conscious thinking.

In the discussion, however, it will emerge that the position that our account occupies is not defined by the contrast between naturalism and phenomenalism, but between the latter and sensory inner speech views, in that it has interesting commonalities and differences with each of them.

\section{Cognitive Phenomenology and Content Individuation}

The phenomenal intentionality framework has allowed some authors to present a new perspective on the problem of thought - content indeterminacy. A seemingly natural suggestion within this family of views is the idea that phenomenal consciousness gives rise to determinate content. The version of this general claim that interests us here is the view that cognitive phenomenology ${ }^{3}$ grounds thought contents, or gives determinacy to thought contents (i.e., the propositional contents of episodes of thinking) ${ }^{4}$. A prominent way in which the view that the intentional content of thought is determined by its phenomenal character is defended, is through the appeal to our introspective capacities to individuate thought contents, i.e., to say that phenomenal character allows us to know what it is that we are thinking. Pitt (2004) presents the most important detailed argument leading to this conclusion. The argument aims to show that thoughts have a proprietary, distinctive and individuative phenomenology: phenomenal character allows us to consciously and non-inferentially distinguish between thoughts

\footnotetext{
${ }^{3}$ For an overview of the cognitive phenomenology debate, see Bayne and Montague (2011), Breyer and Gutland (2016) and Jorba and Moran (2016).

${ }^{4}$ Within phenomenal intentionality views, it would be possible to claim that it is sensory phenomenal character that grounds thought-content determinacy; but as far as we know, nobody has defended such a prima facie implausible position.
} 
and other kinds of episodes, to differentiate each thought content from every other one, and to individuate the thought as the thought it is. ${ }^{5}$

Our interest here lies in the individuative claim, which precisely amounts to the solution offered by phenomenal intentionality views to the problem of indeterminacy: it is the individuative phenomenal character that presumably allows us to individuate the thought as the thought it is: to pick out this particular thought and not another one. If the thought content did not have the phenomenal character it has-i.e., if it did not appear to us in the way it does-it would not have the content it has, not because contents and phenomenal characters correlate or are linked in some way, but because phenomenal characters metaphysically individuate contents. According to Pitt (2009), the individuative thesis that the argument from self-knowledge proposes should be understood as the claim that an episode of thinking has a certain content, $p$, as its content, because it tokens a phenomenal type that is the intentional content that $p$.

Another view in cognitive phenomenology that presents a version of the individuative claim is Strawson's (2008), where cognitive content is partially determined by phenomenal character, and jointly also by both an external causal element and a conceptual role aspect. In Strawson's case, the partial individuation claim is proposed as the only viable way to solve the problem of indeterminacy (Strawson, 2008: 295ff). Besides these specific approaches to the individuative claim as it applies to thought contents, defenders of phenomenal intentionality more broadly embrace similar claims regarding content in general, which in turn implies determination of

\footnotetext{
${ }^{5}$ The exact formulation of the argument is as follows (Pitt, 2004: 7-8): "Normally (...) one is able, consciously, introspectively and non-inferentially (henceforth, 'Immediately') to do three distinct (but closely related) things: (a) to distinguish one's occurrent conscious thoughts from one's other occurrent conscious mental states; (b) to distinguish each of one's occurrent conscious thoughts each from the others; and (c) to identify each of one's occurrent thoughts as the thought it is (i.e., as having the content it does). But (the argument continues), one would not be able to do these three things unless each (type of) occurrent conscious thought had a phenomenology that is (1) different from that of any other type of conscious mental state (proprietary), (2) different from that of any other type of conscious thought (distinct), and (3) constitutive of its (representational) content (individuative)". (For a version of this argument applied to cognitive attitudes, see Jorba (2016)).
} 
thought content. ${ }^{6}$

We would like to note that it certainly appears quite mysterious why such a powerful role should be attributed to phenomenal character alone, at least in the case of propositional thinking, where part of the explanation depends on purely structural features. Indeed, defenders of phenomenal intentionality do not normally explain how it is that (cognitive) phenomenal character can deliver determinacy of thoughts: "how can [cognitive] experience ever deliver determinateness? It just can. Cognitive experience in causal context can do just this" (Strawson, 2010: 351). It seems to us that the absence of an explanation at this point, which is often taken as a primitive starting claim for further theorizing, is a weakness of the sort of phenomenal intentionality views explored here. In fact, it is even possible to grant that thought contents have a certain proprietary and distinctive phenomenology, without committing to the individuative thesis. We take it that phenomenal character will be content-individuative only if there is no plausible alternative way to individuate contents. Otherwise, this individuation thesis only establishes that phenomenal characters and contents correlate, such that it is possible that while we identify thoughts by means of their phenomenal characters, this only amounts to epistemic — not metaphysical—individuation (i.e., identification) ${ }^{7}$. Pitt's epistemic argument, thus, establishes the individuative claim only in the absence of a plausible alternative hypothesis concerning how contents are metaphysically individuated. A (reductive) naturalistic theory of thought content would claim that contents are individuated by causal or historical relations that hold between the organism and the environment; but, as explained, defenders of cognitive phenomenology are usually suspicious of extant naturalistic accounts. Our proposal is

\footnotetext{
${ }^{6}$ Accounts of the general determinacy claim have been defended by Loar (1995), Horgan and Tienson (2002), Graham et al. (2007), Horgan and Graham (2012), Kriegel (2014) and Farkas (2008), among others (see Kriegel, 2014, for an overview). There has also been resistance to the claim that thought content is phenomenally individuated (see, e.g., Wilson, 2003; Pautz, 2013).

${ }^{7}$ The account that we find more plausible is that phenomenal characters supervene on contents.
} 
that there is an alternative explanation of what determines the content of an episode of conscious thinking, such that the alleged distinctive phenomenal character of a thought content would individuate it only in the epistemic sense (i.e., it would be just a way of identifying it).

To pave the way, we will start by briefly presenting what seems to be the most common reaction to Pitt's argument from those who reject cognitive phenomenology.

\section{Thinking and Inner Speech}

One line of response to Pitt's argument outlined above is to claim that we are never acquainted with thought contents or with episodes of pure thinking. Rather, we are only acquainted with imagery, including acoustic/phonological imagery, and with imagistic and inner speech episodes. This view still defends that we are able to know what we are thinking, though neither by acquaintance nor in any other way that does not involve inner speech or other forms of imagery. This kind of account has been endorsed by a number of authors with different sensibilities (e.g., Byrne, 2011; Prinz, 2011; Jackendoff, 1996; Carruthers, 2011, 2014; Bermúdez, 2003). The idea that these authors defend is that we can be, and are actually, only acquainted with the sensory/perceptual vehicles of our thoughts, because sensory/perceptual phenomena exhaust our phenomenal world: our brains are such that we can only experience the tokening of representations at the sensory/perceptual level (Prinz, 2011; Carruthers, 2014). ${ }^{8}$ However, knowledge of our thought contents is acquired by forming beliefs on the basis of that sensory evidence. Beliefs can yield knowledge because the belief-forming mechanism in question is a reliable one. This belief-forming mechanism is the same one that we use to form beliefs about what other people think when they speak. For

\footnotetext{
${ }^{8}$ For a discussion of these views in relation to their prospects of explaining our access to thoughts contents, see Jorba and Vicente (2014).
} 
Carruthers, for example, the mechanism that forms the belief that the other person thinks that $p$, takes the words uttered by the other person as input, and processes it via the linguistic and the pragmatic, mind-reading, systems (either in tandem or serially). The output of the process is the belief that the other person thinks a certain thought content, specifically, the thought content expressed by their words (Carruthers, 2011, 2014). This process is entirely subpersonal and modular, so there is no step at which the subject is or needs to be aware of the thought content expressed by the other person's utterance. When this system is activated not by overt outer speech but by our own inner speech, neither do we know, nor are we able to know, what we think by being acquainted with our thoughts through experience; we know what we think by interpreting the acoustic representations we self-generate and experience.

This is, roughly, the view that deniers of cognitive phenomenology have ready to hand to account for self-knowledge, and which we will call 'sensory inner speech views', because of their reliance on the sensory aspects of inner speech. One implication of this approach is that there is no non-interpretative or non-inferential way of knowing our thought contents, which directly opposes Pitt's (2004) immediacy claim. ${ }^{9}$ According to sensory inner speech views, knowledge of our own thoughts must always be mediated by our interpretation of sensory elements. Interpreted sensory elements, when expressing a certain propositional attitude, constitute an episode of conscious thinking ${ }^{10}$. We thus know the content by interpretation and the vehicle by acquaintance.

\footnotetext{
${ }^{9}$ Pitt rejects the idea that immediate knowledge of thought contents is possible on the basis of the sensory phenomenology involved in thinking those thoughts, given that someone could have the relevant image without thinking the corresponding thought: "even if thoughts are, as a matter of fact, usually or even always accompanied by some kind of auditory or visual imagery (so that such imagery is part of the total phenomenology of a conscious thought) - or even if such imagery is necessary for thinking a thought - it is not identical to the thought, and it is not in virtue of introspecting such experiences that one introspectively knows what one is thinking" (Pitt, 2004: 24).

${ }^{10}$ Perhaps not all episodes of inner speech express propositional attitudes. For instance, one important function of inner speech is self-motivation. If you tell yourself, in the middle of a climb 'go on!', would
} 
Importantly for our purposes here, the sensory inner speech view also has implications for the individuative claim. As we have seen, according to Pitt and other defenders of cognitive phenomenology, the phenomenal character of a thought determines its content, and a reason to maintain this is that no other account is in a position to explain the determinacy of the content of our thoughts that is consistent with self-knowledge. However, if the content of a thought is related to linguistic expression, as in sensory inner speech views, the determinacy problem does not arise; or at least, it does not arise as forcefully as it does in a reductive naturalistic theory of content determination. To the extent that utterances have determinate contents, provided by the contents of their constituent parts and the way those parts are arranged, it can be said that the content of a conscious thought is not given by its phenomenal character, but by the semantics of a language ${ }^{11}$. The semantic representations of a language represent categories in the world, and syntax provides a means to generate predicative constructions, i.e., expressions that can be true or false. The interpretation of a phonological string, thus, can provide meaning representations expressing nonambiguous, determinate, predicative relations that can be true or false. There are some questions that an account such as this has to answer, the most pressing being how language could play a role in content determination, given that language is supposed to merely reflect the intentionality of thought. Given that a particular version of this general approach will constitute the ultimate response we will also provide to the individuative claim, we will postpone the discussion of this question till later. First, we will explain why the sensory inner speech approach faces an important problem.

we say that you are expressing a propositional attitude, and so that you are thinking something; or would it just be a non-propositional way of motivating yourself?

${ }^{11}$ Note that we are talking about the semantics of an utterance, not the semantics of a sentence, which is plausibly underdetermined (Vicente and Martínez-Manrique, 2008). 


\section{Unsymbolized Thinking}

A relevant problem for the defenders of the sensory inner speech view is the existence of unsymbolized thinking (UT). We can distinguish between two different types of thinking episodes: those that involve the presence of strings of words or inner speech (or some other sort of imagery), and those that do not. Normally, when thinking silently, many people report 'talking to themselves', so that inner speech is recognized as one pervasive phenomenon in our inner lives (Heavey and Hurlburt, 2008; Klinger and Cox, 1987-88). Thinking with the presence of inner speech is not, however, the only way we think propositional contents. Some studies defend the existence of UT (Hurlburt and Akhert, 2008; Hurlburt, 2011): experiences of thinking particular thoughts that do not include the experience of any other "symbols", such as phonemes or imagery ${ }^{12}$. This kind of experience is described as one of the five most common features of inner experience - the other four being inner speech, inner seeing, feelings and sensory awareness (Hurlburt and Akhert, 2008). These studies make use of the descriptive experience sampling method (DES). DES is a method that attempts to capture what Hurlburt calls "pristine inner experience": inner experience as it directly presents itself in a natural environment. The method consists of two phases. In the first phase, subjects carry around with them in their everyday life a beeper that beeps at random intervals, and they note down whatever they are experiencing when it beeps. In the second phase, they tell the researcher what they have noted down, and the researcher asks them questions about the particular experiences that they could discriminate at the

\footnotetext{
${ }^{12}$ Introducing the phenomenon as not involving any 'symbols' is misleading, as it might suggest that the thinking in question is carried out without any symbols or representations of a natural language, something that, we will suggest, may be false. However, we have followed the use of the term as it appears in the relevant literature. An example of an instance of UT, which will be discussed below, is the following: "Dorothy is tiredly walking down the hall dragging her feet noisily on the carpet. She is thinking, if put into words, something quite like, 'Pick up your feet—it sounds like an old lady'... Despite the lack of words, the sense of the thought is very explicit: 'pick up your feet' is a more accurate rendition of the experienced thought than would be 'I should pick up my feet'; and 'it sounds like an old lady' is more accurate than 'I sound like an old lady"' (Hurlburt and Akhert, 2008: 1364).
} 
moment of the beep. These questions help subjects arrive at a more accurate description of their experiences, potentially removing presuppositions and previous preconceptions.

DES in general as well as some of the results (in particular, the existence of UT) that Hurlburt and colleagues report, are far from unquestioned (see Hurlburt and Schwitzgebel, 2007, for an interesting exchange). However, as Hurlburt et al. (2017) comment, there is some evidence that they can adduce in favor of what they consider to be their "observational" methodology. Starting with Kühn et al. (2014), Hurlburt and colleagues have combined DES with fMRI scans, and have observed, for instance, that a previous distinction they had drawn on the basis of subjects' reports between inner speaking and inner hearing, corresponds to the activation of different areas in the brain (related, respectively, to language production and comprehension). To date, it seems that the fMRI results are compatible with the claims and distinctions made on the basis of DES. Notwithstanding, DES seems to be more reliable, careful and theoretically grounded than other methods that researchers have used when trying to access inner experiences, such as questionnaires or pure introspection.

There is still no direct evidence from fMRI studies of the existence of UT, although the evidence that there is in favor of DES should count as indirect evidence for the reality of UT. Meanwhile, sceptics regarding UT who have not questioned DES in general have been unable to produce alternative explanations of the phenomenon (see Hurlburt, 2011, for defense of the reality of UT). The problems that have been raised concerning UT results include: the suggestion that reports of UT may stem from confabulation (Engelbert and Carruthers, 2011); that there may be a masking effect resulting from the beep used in the experiments (Tye and Wright, 2011); and that UT is not, after all, totally devoid of sensory/perceptual representations (Byrne, 2011). None of these reactions seems to work. There is no reason why subjects should report that 
they are experiencing UT instead of experiencing inner speech or imagery or whatever, so it is not clear why they should be confabulating. In fact, when they experience UT, they are typically genuinely surprised ${ }^{13}$. Next, if UT only occurred because the beep masked the imagery that is being produced right at the moment of the beep, we should expect all subjects to report UT, as the beeper would have a masking effect on all subjects, at least sometimes. However, there are people who do not report UT at all (there are also people who report very infrequent, if any, inner speech: see Hurlburt, 2011; Hurlburt et al., 2013). Given this, how can the masking hypothesis explain the fact that some people do not experience UT? Finally, it is true that Hurlburt (2009: 149150) concedes that "the apprehension of an unsymbolized thought may involve the apprehension of some sensory bits, as long as those sensory bits are not organized into a coherent, central, thematized sensory awareness". ${ }^{14}$ However, this is the only time he mentions the existence of 'sensory bits'. Typically, Hurlburt talks about UT simply as "the experience of an explicit, differentiated thought that does not include the experience of words, images, or any other symbols" (Hurlburt and Akhter, 2008: 1365). More importantly, the sensory bits in question do not make up an eventual vehicle of the thinking. That is to say, even if UT involved some sensory bits, it would still be a different phenomenon from inner speech, inner seeing, feelings and sensory awareness.

Meanwhile, it has to be noted that the experience associated with UT is not just the experience of an episode of thinking in the absence of the experience of inner speech or some other sensory vehicle; it is also the experience of thinking a particular thought, i.e., a particular content. Both aspects of the overall experience are

\footnotetext{
${ }^{13}$ Hurlburt and Akhter (2008: 1336) make the following observation about the report made by one subject: "note that Evelyn appears helpless, powerless in the face of her own observation of her experience. Her expression conveys something like the following: I know this sounds weird, and I don't think it's really possible, but you asked me to tell you exactly what is in my experience and this is it. Sorry it doesn't conform to your expectations, but this is what I was thinking".

${ }^{14}$ The presence of these sensory bits has been used by Byrne (2011: 122), for instance, to argue that UT does not present a problem for views that rely on the presence of inner speech to account for knowledge of thought contents. For a response to Byrne, see Samoilova (2015).
} 
problematic for defenders of the sensory inner speech view, especially if they aim to explain the determinacy of thought content in terms of strings of phonemes.

Now, concerning the second, content-related aspect of the phenomenology of UT, Hurlburt and colleagues can easily find allies in defenders of cognitive phenomenology who, by means of phenomenal contrast arguments, argue that we do experience the contents of our occurrent cognitive episodes. One such argument consists of inviting the reader to compare two readings, each with a different meaning, of an ambiguous sentence such as 'the girl saw the Martian with a telescope'. It seems that there is a phenomenal contrast when you move from one reading (the girl has the telescope) to the other (the Martian has the telescope). Some defenders of cognitive phenomenology would not stop here. Either by means of phenomenal contrast arguments that do not involve the production of any kind of sensory experience (Kriegel, 2015) or by means of detailed descriptions of what they introspect (Siewert, $1998)^{15}$, they typically argue for the reality of the overall experience that Hurlburt and colleagues identify with UT: experiencing non—sensorial thinking, and experiencing its content. That is, the existence of UT may be surprising at first, but philosophical reflection may provide grounds that support its existence.

We take it that, overall, it is plausible to believe in the reality of UT. The point now is that for UT, the sensory inner speech account is clearly not available. Indeed, UT

\footnotetext{
15 On the one hand, Kriegel (2015: 56) presents the case of Zoe, a sensory-algedonic-emotional zombie that happens to be a mathematical genius and, after struggling with a mathematical problem, she "sees" the solution. On the other hand, Siewert presents the case of thoughts that are a type of "noniconic thought', where neither images nor verbalizations are involved: "Walking from my table in a restaurant to pay the bill, I was struck briefly by a thought, gone by the time I reached the cashier, about my preoccupations with this book's topic, the effects of this, and its similarity to other preoccupations and their effects. Asked to state more precisely what this was, I would have to say something like: 'My preoccupation with the topic of my book has made the world seem especially alive with examples of it, references to it, so that it can't help but seem to me that the world is more populated with things relevant to it than previously. And it struck me that this is similar to the way in which new parenthood made the world seem to me burgeoning with babies, parents, the paraphernalia of infancy, and talk and pictures of these'. Somehow this thought of my philosophical preoccupations and parenthood, and an analogy between their effects, rather complex to articulate, occurred in a couple of moments while I approached the cashier, in the absence of any utterance" (Siewert, 1998: 277).
} 
requires an approach that acknowledges non-sensory mediation of our knowledge of contents: something that sensory inner speech views simply deny could exist. Regarding episodes of UT, and our knowledge of their contents, Pitt's approach looks much better placed as an explanation. However, we do not think it is necessary to invoke the metaphysical individuative claim in order to explain how the contents of UT are determined. To see why, we will present our own view of how UT is generated. This view accounts for how the contents of UT are determined in the same way it accounts for how the contents of our inner speech utterances are determined, although the view is itself different from sensory inner speech approaches.

\section{Unsymbolized Thinking as Aborted Inner Speech}

The account we want to introduce construes UT as a phenomenon that is closely related to inner speech. Let us begin by explaining how, according to current theories, the inner voice is produced, which is not very different from how external speech is produced. The explanation is that first we form a certain high-level, subconscious intention to express something, a content that can be more or less structured (see below). We then go through a series of steps, which can include a certain, maybe high, degree of back and forth (Hickok and Poeppel, 2007), where we flesh out that highlevel, programmatic intention, giving it form in terms of semantic and syntactic structures, phonological representations, and finally articulatory instructions, or motor commands, to produce sounds. This is the part where inner speech does not differ from outer speech. However, unlike in overt outer speech, right after the motor command is issued, it is inhibited. There is time, however, for the monitoring system to receive a copy of the motor command and to predict what will happen when the motor command is realized (what signals the body is going to receive). According to many proponents of 
this theory (e.g., Jeannerod, 2006; Carruthers, 2011; Guillot et al., 2012; PerroneBertolotti et al., 2014), when something like this happens, i.e., when in general a motor command is inhibited, the result is imagery: if the motor command concerns producing speech sounds, the result is the phenomenology of inner speech, i.e., our inner voice. Plausibly, the phenomenology of inner speech is generated by making conscious the prediction that does not match any actual output (Carruthers, 2011; Pickering and Garrod, 2013; Swiney and Sousa, 2014). In general, simulating is making a prediction conscious (Jeannerod, 2006).

This theory draws on the corollary discharge model of perception proposed by Helmholtz (1860), and extended by von Holst and Mittelstaedt (1950) and Sperry (1950) to deal with motor acts. The model, in general terms, works in the following way: whenever a motor command is issued, the brain predicts, based on an efference copy (or corollary discharge) and the work of some 'forward models', what proprioceptive and sensory feedback will ensue. This prediction is used, together with a prediction of how the motor command will be executed, to monitor the execution of the motor instructions. Both predictions are used to detect errors in execution. The prediction of incoming signals is used to detect errors, through comparison with the actual sensory signals received. If the prediction matches the signal, the action is selfascribed - maybe generating the 'sense of agency' (Feinberg, 1978; Frith, 1992, 2012). When the monitoring system does not work properly, subjects may end up experiencing their actions as alien, as in passivity phenomena such as control delusion, auditory verbal hallucinations, and thought insertion (Feinberg, 1978; Frith, 1992).

Now, this is a theory of how the inner voice is produced, and it focuses only on motor commands and predictions related to sensory signals. However, predictions, given their monitoring role (Hickok, 2012), are plausibly issued at different levels 
(Pacherie, 2008). In the case of speech, some influential psycholinguists argue that the production system issues predictions at many levels: at least concerning semantics, syntax and phonology (Pickering and Garrod, 2013; Garrod et al., 2013; Gambi and Pickering, 2016); or at the 'formulator' (semantics and syntax) and the articulator (motoric) levels (Hartsuiker, 2014). Pickering and colleagues argue that typically, overt speech comparisons for error detection do not use the auditory input of the subject's own voice, but work on the basis of the predictions issued at the different levels. Error detection and repair is too quick to rely on comprehension of the external input (i.e., overt speech). On their account, semantic errors, such as selecting a meaning or semantic representation that does not correspond to the intended meaning, are detected and corrected very quickly (in about $300 \mathrm{~ms}$ ). This suggests that the error is spotted and the correction made on the basis of the predicted meaning ${ }^{16}$. Noteboom and Quené (2017) further support this general model by distinguishing two ways of detecting errors: internally (i.e., via predictions) and externally (via auditory input or proprioceptive/articulatory information). To detect an error in the second way takes about $500 \mathrm{~ms}$ longer than to do so internally, and repair is even more costly in terms of the time required: $700 \mathrm{~ms}$ longer than error repair using the internal, predictive system.

We want to highlight at this point that if a prediction of the sound of a speech act is the inner voice, a prediction of the full semantics of a speech act will be the

\footnotetext{
${ }^{16}$ Semantic errors consist of substituting the intended meaning for some other meaning that is close to it in the semantic network or similarity space. A famous error (cited by Dell, 1995) is former US president Gerald Ford saying to Anwar el-Saddat, then president of Egypt, "the great people of Israel -Egypt, excuse, me". In general, speech errors can be induced in the lab by making people repeat lists of words or sentences, or by priming subjects with words or meanings that can interfere with production. Semantic errors are induced by making people entertain notions that have strong connections with the words that they have to produce. Given that the selection of a meaning has always been thought to be the first step in speech production, semantic errors (the "Egypt-excuse me" part of Ford's utterance) should be the first ones to be spotted if people do not rely on actual production for repair. Noteboom and Quené (2017) show that there is indeed a way in which we detect and begin to repair all sorts of errors before they are spoken or our muscles start moving. First, they show that there are two ways to spot and repair an error, one which is much faster than the other. Secondly, they show that most errors are spotted even if subjects are in an environment so noisy that they are unable to hear their own voice.
} 
meaning/content of such a speech act. That is, a prediction of the full semantics of a speech act is nothing other than what we identify as a propositional content. It is plausible to believe that our typical inner speech is not just a string of auditory representations or an inner voice; rather, it has sound-like properties and meaning. How could this be? Carruthers' view is that we bind the content of what we have said in our inner voice after interpreting our inner utterance via the comprehension system (Carruthers, 2011, forth.). Another possibility, however, is that our inner speech already 'comes' with a meaning. As we have said, when we form the intention to express a certain content and we refine that intention to the point of executing the motor commands that ultimately realize it, we issue predictions not just of how the utterance is going to sound, but also of what it is going to mean. Now, if instead of executing the motor command, we inhibit it, it may be that what enters our consciousness is not just an acoustic image, but an acoustic image with a meaning ${ }^{17}$, given that we have issued both kinds of predictions. There is no reason why only the prediction related to the motor command should be conscious (that is, unless one is independently committed to the view that only sensory states are conscious). The way we experience inner speech, in contrast, is very often as if we were thinking in words, that is, as if our inner voice were the vehicle of our thoughts. This part of the phenomenology of inner speech can be explained if the inner voice comes with its meaning attached; in our terms, if the prediction of the acoustics is accompanied by a prediction of the meaning ${ }^{18}$.

Now, what would happen if an instruction to speak never reached the motoric component? Suppose that instead of inhibiting our intention to express some thought content at the level of speech commands, we inhibited it at a previous level, say, at the

\footnotetext{
${ }^{17}$ Arguably, some cases of inner speech are meaningless, as if you were to repeat to yourself a list of numbers to keep them in your memory. But in such cases, we never form the intention to express a thought.

${ }^{18}$ For a view similar to this one, albeit different in the details, see Gauker (forth.).
} 
level where we have given form to our intention in terms of semantics and syntax, but not yet in terms of phonology. In such a case, we would still have issued a prediction concerning the meaning of the utterance we were intending to make. What would happen next? According to the model, the prediction would be made conscious, presenting to you the content of the utterance you did not make, which would come in a linguistic format, i.e., with the structure and semantics of a sentence of the language you use to talk to yourself ${ }^{19}$. This would be an episode of UT: an episode involving a thought with a propositional content but with no sensory accompaniment. Thus, in our construal, episodes of UT have as contents precisely the contents that a subject intends to express once they have been structured according to that subject's language (Martínez-Manrique and Vicente, 2015, Vicente and Martínez-Manrique, 2016) 2021.

\section{The Linguistic Nature of Unsymbolized Thinking}

Our account of UT maintains that the content of UT are not 'thoughts' properly speaking, but meanings of utterances we have aborted ${ }^{22}$. That is, we do not experience a UT just by thinking, but by forming the intention to express a content and then aborting it. We think that this view of UT accords with and can be seen as a continuation of inner speech, and is appealing once the inner voice is seen as being derived from aborted

\footnotetext{
19 Not all authors believe that the inner voice is a prediction of the sounds we would hear (see Oppenheim, 2013). However, the take-home message is that if the generation of the inner voice is related to aborting an intention at some level (say, at the level of motor commands), it makes sense to think that the generation of a conscious, unsymbolized episode of thinking is related to aborting an intention at a previous level.

20 'Language' and 'linguistic' are used to refer to all the representations and mechanisms involved in the typical production of utterances in a particular natural language (even if an utterance is not produced because production is inhibited). Note that this account implies that only linguistic animals will experience episodes of UTs.

${ }^{21}$ For a similar view, see H. Lœvenbruck et al. (forth.)

${ }^{22}$ One could object that the idea that instances of UT are not thoughts properly speaking is a problem at the level of phenomenology because it might suggest that subjects misconstrue their experience of UT when they report it as thinking and not as a form of inner speech, for example. The fact is that there certainly is a proprietary experience of UT, but is it one of thinking? It seems that we cannot know: the only thing we do know is that we talk about it as thinking, and the same happens many times with inner speech. This seems to be the most we can say at the level of phenomenology.
} 
commands. However, we will try to make our view plausible in itself by focusing on the nature of $\mathrm{UT}^{23}$.

Firstly, the view makes UT continuous not only with inner speech (and, e.g., muttering to oneself), but with other phenomena that Hurlburt and his collaborators have uncovered, such as partially unworded and totally unworded inner speech (see also Martínez-Manrique and Vicente, 2015; Vicente and Martínez-Manrique, 2016). According to Hurlburt et al., (partially or totally) unworded speech refers to episodes in which subjects regard their inner experience as a variety of inner speech in which there are parts missing. This is better understood in the cases of partially unworded speech, such as "you experience yourself as speaking, 'That is a very strong - maybe it is a gas leak!' with a temporal space reserved for the word 'odor' but the word 'odor' itself is not actually in your experience" (Hurlburt and Heavey, 2006: 211). There is, however, a more puzzling category distinguished by Hurlburt and collaborators in their analysis: the case of totally unworded speech—or unworded speech, simpliciter. This is "the experience of speaking in your own inner voice except that you have no experience of words at all" (2006: 211). They characterize experiences of unworded speech as instances in which "you have the sense of speaking, and are directly aware of the vocal characteristics of that speaking (rate, inflection, timbre, rhythm, etc.), and are directly

\footnotetext{
${ }^{23}$ An apparently simple way to explain UT, which is in broad agreement with naturalistic approaches to content determination, is as follows. Our thought contents (of our propositional attitudes) are the contents of Mentalese sentences that we token in our minds/brains. Usually, these thought contents are not conscious; however, if we attend to the episodes they form part of, or, alternatively, if we embed them in another Mentalese sentence, we can experience them. A problem with this sort of proposal is that there is no extant explanation of how we can convert the tokening of an LoT sentence into an experience of thinking a thought, that is, an experience related to the content (and no other properties) of the thought, and to us doing something - the experience of agency. Levine (2011), in fact, uses the Mentalese hypothesis to explain how we could have knowledge of our own thoughts without experiencing anything at all. This problem by itself does not rule out the Mentalese explanation, since it may be that future developments of the LoT hypothesis tackle the issue of how the tokening of a Mentalese sentence can give rise to the experience of thinking a thought. So we cannot discard the idea that contents of UT are tokenings of Mentalese sentences; although we also want to note that no Mentalese story has yet explained what determines the denotations (contents) of mental representations-which is the issue that defenders of the individuative claim hold is still problematic.
} 
aware of the meaning of what is being 'said,' even though no words are present" (2006: 211-12). What we seem to have here is a gradation, at the level of sensory experience, that goes from expanded (i.e., non-fragmentary) inner speech to UT, plus the preservation of: (i) the experience associated with meaning in all cases; and (ii) many of the situations typically associated with inner speaking (Hurlburt et al., 2013) ${ }^{24}$.

As we have said, when we have an experience as of an inner voice, we usually also have an experience associated with its meaning. Very often, we claim that we think in inner speech. Our experience, thus, is not restricted to the acoustic part of inner speech, but includes content — as opposed to those cases where we use the inner voice just to hold some information in memory. This holds for all the different formats that inner speech may take according to Hurlburt's classification: expanded, fragmentary, partially unworded and totally unworded inner speech. UT would be an extreme case, where only the content of inner speech is experienced. The difference between UT and unworded speech would be that the former lacks the experience of sequentiality or 'unfolding'. However, there seems to be no clear situation of use of UT that distinguishes it from inner speech. Both UT and inner speech can be involved in 'hard' tasks (like looking for your keys) as well as in 'lighter' ones (such as commenting on what you are seeing). We will probably not find UT in preparing a lecture, or rehearsing a dialogue, but this should not be surprising.

Secondly, Hurlburt and Akhter (2008) tell us that instances of UT have an explicit and differentiated content, such that the 'about what' and the 'what about it' are plainly apprehended and are not general or vague. Moreover, reports can make finegrained discriminations between contents, as exemplified by this quote:

\footnotetext{
24 This apparent continuity is also highlighted by Hurlburt and colleagues: "As a result, the DES method [...] would conclude that Susan's apprehensions of her pristine experiences include a range of completeness in the inner expression of words, ranging from quite completely expressed with explicitly apprehended prosody... to innerly speaking with implied words ... to thinking without words at all ..." (Hurlburt et al., 2017: 8). On this continuity point, see also Lœvenbruck et al. (forth.).
} 
"Dorothy is tiredly walking down the hall dragging her feet noisily on the carpet. She is thinking, if put into words, something quite like, 'Pick up your feet-it sounds like an old lady'... Despite the lack of words, the sense of the thought is very explicit: 'pick up your feet' is a more accurate rendition of the experienced thought than would be 'I should pick up my feet'; and 'it sounds like an old lady' is more accurate than 'I sound like an old lady"' (2008: 1364).

Explicitness and the ability to choose, and stick to, some phrasing instead of some other, show that UT has an easy interaction with the verbal system. Contents of UT have predicative structure, and they come 'formatted' in a structure we can easily recognize. It may be that they even come with a certain order, i.e., head-final or headinitial. This point has not been explored in the literature, but we think it is a plausible hypothesis in order to explain reportability. This would convert contents of UT into linguistic items already linearized and ready for emission.

Thirdly, UT is typically experienced as thinking, that is, as something we are doing. Where does this sense of agency come from? Our view allows for an explanation as to why we feel that we are the agents of our UT. As we have mentioned, according to an influential account, we experience the sense of agency when the signals coming from the world and our body match our predictions. We think that we can explain the sense of agency experienced when thinking if we move in that direction. Even though the application of the model to the cognitive domain may not be straightforward (see, e.g., Frith, 2012; Vicente, 2014), it is plausible that models such as those proposed by Rapin el at. (2013), Swiney and Sousa (2014) and Lœvenbruck et al. (forth.), which explain agency in inner speech in terms of comparisons between goal states and predicted states, could also explain agency in UT. The proposal is that we experience agency when thinking because we compare a certain output (UT content) to a desired state. 
It is true, in contrast, that we do not always experience agency in thinking: sometimes we experience what are called 'unbidden thoughts'. However, it may be that unbidden thoughts are a different kind of phenomenon. On the basis of their use of DES, Hurlburt and Heavey (2013) have distinguished between inner speaking and inner hearing: sometimes we feel we are the ones speaking to ourselves, but some other times we feel we are just listening to our own inner voice. In an interesting, already mentioned study using fMRI, Hurlburt and colleagues (Kühn et al., 2014) have seen that the brain areas involved in inner speaking are actually different from the brain areas involved in inner hearing. In general terms, inner speaking is associated with production areas, while inner hearing is associated with comprehension areas. Thus, it may turn out that inner speaking and inner hearing are two different kinds of phenomena. This suggests that thinking and having unbidden, or passive, thoughts, may be two different phenomena as well. In such a case, we might have an explanation for one kind of phenomenon, i.e., for active thinking, and we can hope that we could capitalize on an explanation that accounts for inner hearing (yet to come) in order to explain unbidden thoughts. At any rate, discovering that there is a parallel between UT and inner speech also at the level of agency strengthens the view that there has to be continuity between them.

\section{Aborted Inner Speech and Thought-Content Individuation}

We have so far suggested that our proposal of aborted inner speech is able to explain UT in a way that is continuous with inner speech and presents some explanatory virtues. But how is it related to cognitive phenomenology and its individuative claim?

Suppose that, in effect, each UT content has a distinctive phenomenal character. Would this mean that the content of UT is given, and so determined, by such 
phenomenal character? We think that our model has important consequences for the question of the determinacy of content, and that it might also have some for the relation between conscious and unconscious intentionality.

Above, we said that Pitt's argument only establishes the individuative claim if phenomenal character is the only candidate available for content individuation. Even if each content has a distinctive phenomenal character, and even if we epistemically identify the contents of our thoughts via their phenomenal character, it does not follow that such phenomenal character is content individuative in the metaphysical sense. It is possible that phenomenal character supervenes on the real content-determining factors. If such a supervenience claim is correct, then we have reason to think that phenomenal character is a reliable means by which to know the content of a thought ${ }^{25}$. Even if phenomenal character plays this epistemic role, the view we have proposed is that the content-determining factors are linguistic: the content of a conscious thought is given by the content of its constituent semantic representations and the way these are syntactically combined. In this specific respect, our proposal coincides with the account that the sensory inner speech views presented above could advance, except that they cannot account for the case of UT.

Note, though, that in section 3 , we left an issue open. We argued that defenders of the sensory inner speech approach could hold that thought propositional contents are provided by language. But then we asked how it could be that language played that role if, allegedly, language is a representational tool that derives its intentionality from thought, i.e., if language just expresses thought. Now it is time to tackle this question, given our appeal to linguistic mechanisms. There are two general ways one could proceed that could fit in with the picture we have advanced. The first, more conservative

\footnotetext{
${ }^{25}$ Thanks to an anonymous referee for calling our attention to this point.
} 
route, is to grant a Gricean perspective on linguistic production, according to which we form intentions to express a determinate propositional content. The second, stronger route, is to deny the Gricean view and the presumption that language is a means of expressing, inter alia, pre-existing propositional contents. In the first case, we will argue that the determinate contents of our conscious episodes of thinking (delivered by our linguistic production system) are the result of a process of representational redescription and so differ from the alleged determinate contents of non-linguistic thought. In the second case, we will present some ideas that could support a split between unconscious, non-determinate and non-linguistic thinking, on the one hand; and conscious, determinate and linguistic, thinking, on the other.

The conservative approach maintains that unconscious thoughts, in virtue of being something akin to Mentalese representations, for instance, are in general just as determinate as conscious thoughts are. That is, the message that we want to convey by uttering a certain linguistic representation has a predicative but not a linguistic format ${ }^{26}$, and a determinate truth-conditional content ${ }^{27}$. This is, basically, the orthodox, good old-fashioned picture present not only in philosophy, but also in speech production: it is Levelt's model (Levelt, 1989). However, note that even if this model were adopted, it can still be claimed that the content of our conscious thoughts is not given by the content of the thought we want to express, but by the semantics and the syntax of our language. That is, even if the thought content we want to express is allegedly fully determinate, it has to undergo a process of representational re-description in order to

\footnotetext{
${ }^{26}$ By non-linguistic here we mean that the thought to be expressed does not use the apparatus of a natural language but is supported by some other vehicle such as Mentalese. It is also a possibility that the message to be conveyed is linguistically supported and structured. This is Chomsky's idea that we use language - not LoT-for thinking, and that speaking consists of externalizing an already linguistically structured message (Chomsky, 2016). In this case, the content of most or all (proper) thinking, conscious and unconscious, is given by linguistic representations.

${ }^{27}$ Critics of the naturalist program would of course complain that proponents of such an account still owe an explanation of where this determinate truth-conditional content comes from. We are leaving this worry to one side for the moment.
} 
take on a linguistic form. It is a matter of contention how much re-description such a process involves; but we take it that it is plausible to think that, besides formatting according to a grammar, the re-description also involves the recruitment of semantic representations that do not map neatly onto our conceptual structures (Malt and Majid, 2013), such that the truth conditions of the thought content we want to express are not identical to the truth conditions of the utterance we produce as the expression of that thought content. In particular, if the determinacy of our non-linguistic thoughts is given by the contents of something akin to Mentalese representations, which by and large are supposed to be universal, we have reason to believe that those contents have to be poured into a very different mold for them to be expressed in our language, given how little the categories drawn by one language in one domain have in common with the categories drawn by a different language in the same domain (even in "simple" cases such as colors, space or spatial relationships: see Evans and Levinson, 2009) ${ }^{28}$. In the case of colors, for instance, there is mounting evidence that there are two ways of forming categories: one is more or less universal, and the other is diverse and language specific. Interestingly, even at this level, the categorization of colors that involves the left hemisphere of the brain appears to engage linguistic production (Regier and Kay, $2009)^{29}$. So it seems that it is plausible to believe that whenever linguistic production is involved, the categories represented by the system differ from the categories drawn by the non-linguistic systems. In any event, our point is that the content we are acquainted

\footnotetext{
${ }^{28}$ For example: it may be that the way of conceptualizing spatial relations is universal and that we all distinguish tight versus loose containment relations (at least that would be the case if we conceptualize as infants do: see Hespos and Spelke, 2004, for the relevant data and discussion). Thus, if we see a ring on a finger, we-determinacy problems aside - would conceptualize the relation as one of tight containment. Now, when we want to express the eventual thought content that the finger is in a tight-containment relation with the ring, our utterance will say that the ring is on the finger. Note that such an utterance will be true even if the finger is in a loose containment relation with the ring. Note also that our claim is that episodes of UT have contents such as the ring is on the finger, and not contents such as the finger is in a tight-containment relation with the ring.

${ }^{29}$ For more results that point towards a major involvement of on-line uses of language in categorization, see, e.g., Lupyan (2012).
} 
with is given by representations and structures provided by our linguistic systems. That is, what we are conscious of are contents whose determinate truth conditions are given by categories drawn by the words of our language and the structures that constitute the grammar of that language.

The second, stronger and more interesting line of response involves denying the presumption that language is a means of expressing, inter alia, pre-existing propositional contents. It therefore approaches the issue of how the unconscious thoughts that we intend to express relate to the conscious thoughts that we have by exploring the idea that conscious thought contents have a degree of determinacy that unconscious thought contents lack (Crane, 2017). This route would resemble those phenomenal intentionality views that are committed to a disanalogy between conscious and unconscious thoughts, even if for reasons different from ours (see Kriegel, 2014, for a survey of positions). The idea that we want to scrutinize is that thought content needs to be brought to consciousness for its content to be fully determined. Otherwise, our occurrent mental states are not entirely determinate or specific about their contents: to have a conscious thought is not simply to have an unconscious thought that is made conscious by way of attending to it or by broadcasting it. There is something more in this process: 'coming to consciousness' involves attributing determinacy to contents. That is, conscious intentionality is not a derivative kind of intentionality. What could explain determinacy in our picture?

The account of UT that we have proposed so far could explain how it is that episodes of thinking a content that we are conscious of have a determinate aboutness not based on their alleged phenomenal character. Suppose that UT contents are, as we have said, the result of broadcasting predictions issued after the construction of linguistic messages has reached the level of the 'formulator' (Hartsuiker, 2014; 
Lœvenbruck et al., forth.): the level where the thought to be expressed is formatted according to the representations and rules of our language ${ }^{30}$. At this level, the message consists of a predicative structure elaborated on the basis of semantic representations and syntactic rules. Such a message has a determinate content and determinate truth conditions. Regardless of what the thought that we want to express looks like, 'translating' it into our language involves shaping it in accordance with representations of categories in the world which, when composed, represent states of affairs (and thus can be true of false). This is indeed what the content of an instance of UT looks like, and it is the level of determinacy that our conscious thoughts seem to have. So language, intentionality, and consciousness would come together in the following way: content determinacy is given to thoughts via linguistic mechanisms, and this determinacy appears when a certain step of the language production process, i.e., the prediction of the meaning to be issued, is externalized and made conscious (so intentionality appears as such, with determined content, at the conscious level) ${ }^{31}$.

\footnotetext{
${ }^{30}$ An anonymous referee has asked whether speech production could be aborted even earlier (at a higher level of the process). This would indeed be a possibility; but the question is whether there is a level above the level of semantics where a monitoring system issues predictions. None of the extant models contemplate the hypothesis that there is a level of predictions higher than semantic predictions, since there seem to be no errors related to such a level. Now, if the first stage at which we issue predictions in speech production is the recruitment of meanings, aborting at a previous stage, if it could be done, would not in any case result in the production of a conscious experience.

${ }^{31}$ A question we have not entered into concerns the mechanism of how predictions are made conscious. Carruthers (2014, forth.) holds that, just as for any other phenomenon related to consciousness, predictions are made conscious by receiving attention. In Carruthers' view, it is possible that we generate several different predictions on the basis of their corresponding aborted motor commands, and that only one of them is attended to and thus made conscious. We are skeptical of Carruthers' approach, not only because there seems to be little evidence favoring it, but mainly because it seems to depart from the assumption that the forward models system is a monitoring system, i.e., a system dedicated to determining whether a certain output corresponds to our intentions. However, if Carruthers were right, then for every conscious inner speech episode there could be some other, competing, unconscious inner speech episodes that did not receive attention (and the same would hold for semantic predictions). This possibility would complicate the picture we want to put forward. Given that we suggest that thought contents acquire their determination via the linguistic system, with the forward model system making those determinate contents conscious - thus securing a correspondence between determinacy and consciousness - a picture such as Carruthers' would call this strict correspondence into question. Some unconscious thoughts would also have determinate contents: those that are produced by the linguistic system but do not receive attention.
} 
Our unconscious thinking may not be determinate. It is certainly possible that there is no such thing as a LoT, so that unconscious inferences do not work in a language-like medium but, e.g., on representations in conceptual spaces of a prototypical nature (Gauker, 2011) or on map-like representations (Camp, 2009) ${ }^{32}$. Many philosophers working on animal cognition believe that animal thinking is not propositional (see also Bermúdez, 2003). Perhaps it also lacks the sort of determinacy that our thinking has (Glock, 2000). Now, it is not unreasonable to believe that our unconscious thinking is similar to animal thinking. According to such a view, recursivity, productivity, compositionality and determinacy would be properties, not of thought in general, but of the linguistic system. Actually, we think that this latter view is the mainstream one in generative linguistics (Chomsky, 2016; Berwick and Chomsky, 2016); except that in the view of generative linguists, language enables recursivity in thinking without engaging the production system ${ }^{33}$. In our view, to engage the linguistic system and benefit from its properties, we have to speak; and one way of quasispeaking, but close enough to speaking for it to be possible to benefit from the properties of our language, is to produce UT contents.

Now, we can see that our account offers a way to relate (even if in a weak sense) intentionality and consciousness that is an alternative to claiming that phenomenality grounds intentionality. Our account allows us to claim that one aspect of intentionality, namely, determined content, appears at the conscious level, so there is a connection

\footnotetext{
32 There is some debate concerning whether conceptual spaces and maps can produce predicative structures. That is a debate we will not enter into as we mention conceptual spaces and maps only for illustrative purposes, as putative examples of representational systems that could support an interesting cognitive life without necessarily being used to form propositions.

${ }^{33}$ In this regard, Chomsky's view is similar to Spelke's (see Spelke, 2003), which simply claims that the combinatorial system of language enables intermodular thinking. In Carruthers' (2002) development of Spelke's insight, it is not language as such, but the production/comprehension system that provides the possibility of having intermodular thoughts. The contrast between our view and Chomsky's is analogous to this contrast between Spelke's and Carruthers' views.
} 
between intentionality and consciousness ${ }^{34}$. However, the elements responsible for the determinacy of thought contents are provided by linguistic representations and structures; in particular, the syntax and semantics of the subject's own language. In this sense, it is not (phenomenal) consciousness, but language that explains conscious thought-content determinacy. As can be seen, the idea is ultimately in general accord with the view that conscious thinking (system 2 thinking) involves language (Frankish, 2004).

Above, we said that Pitt's argument only establishes the individuative claim if phenomenal character is the only candidate available for content individuation. Even if each content has a distinctive phenomenal character, it does not follow that such a phenomenal character is content_-individuative in the metaphysical sense. It is possible that phenomenal character just supervenes on the real content-determining factors. The view we propose herein is that the content-determining factors are linguistic: the content of a conscious thought is given by the content of its constituent semantic representations and the way they are syntactically combined. In this, the proposal coincides with the proposal that the sensory inner speech views presented above could also advance, except that their proposal cannot account for the case of UT. Here, we cannot give an account of what gives a natural language its semantics (and so in that sense we must leave open the question of how UT acquires its content). Yet, we hope to have provided support for the idea that the project of understanding the content of UT and that of understanding the content of a natural language is one and the same project.

\section{Conclusions}

\footnotetext{
${ }^{34}$ This connection amounts to a correlation between the occurrence of conscious thought and its having determinate content, and in this sense it is a form of weak inseparatism. Relevantly, the view does not embrace the stronger grounding claim that normally accompanies inseparatism according to which conscious thought content is phenomenally determined.
} 
Phenomenal intentionality views defend the idea that intentionality is grounded in phenomenal character. Following this idea, some defenders of cognitive phenomenology make the case for thought or cognition, stating that cognitive phenomenology is content-individuative. We have claimed that this individuative thesis, being a metaphysical claim, is established only if phenomenal character is the only available candidate for content individuation. One alternative may be given by 'sensory inner speech' views, which ascribe the role of determination to linguistic structure and representations, but we have argued that they fail to accommodate the case of UT. Our view construes UT as continuous with inner speech, and the linguistic mechanism underlying both phenomena is what accounts for thought - content individuation, without postulating the metaphysical phenomenal individuative claim. We thus propose an approach to conscious thought content determination that is alternative to naturalistic, sensory inner speech views and phenomenal intentionality accounts; and which has independent plausibility and some interesting consequences for the relation of unconscious and conscious thought.

\section{Acknowledgments}

Versions of this paper were presented at the EPISOC Seminar in the Universidad Autónoma de Madrid (UAM), at the Eastern Division Meeting of the APA in the context of a symposium organized by Mitch Green on "Inner Speech: Its Significance for Self-Knoweldge, Subjectivity, and Communication", and at the "Inner Speech: forms, functions and disfunctions" workshop organized by and the wonderful team at the Laboratoire de Psychologie et Neurocognition, Grenoble. We are very grateful to the audiences in these meetings. Thanks are also due to Charles Fernyhough, Peter Langland-Hassan, Hélène Loevenbruck, Fernando Martínez-Manrique, Jordan Ochs, and Ignacio Vicario. Thanks also to Toffa Evans for linguistic correction. And finally, very especial thanks to Mikel Santesteban and to the two anonymous reviewers provided by Noûs: they could not have been more helpful. Financial support for this 
work was provided by the Ekonomiaren Garapen eta Lehiakortasun Saila, Eusko Jaurlaritza (IT769-13) and by the MINECO, Spanish Government, research projects FFI2014-52196-P and FFI2017-82178-P (A.V. and M.J), FFI2013-47948-P and FFI2016-80588-R (M.J) and postdoctoral fellowship FJCI-2015-23620 (M.J).

\section{References}

Bayne, T. \& Montague, M. (2011). Cognitive Phenomenology: An Introduction, in T. Bayne and M. Montague (eds.). Cognitive Phenomenology. New York and Oxford: Oxford University Press: 1-34.

Bermúdez J. L. (2003). Thinking without Words. Oxford: Oxford University Press.

Berwick, R. \& Chomsky, N. (2016). Why Only Us. MIT Press.

Breyer, T. \& Gutland, Ch. (2016). Introduction, in Phenomenology of Thinking. Philosophical Investigations Into the Character of Cognitive Experiences. London: Routledge.

Byrne, A. (2011). Knowing That I am Thinking, in A. Hatzimoysis (ed.). SelfKnowledge. Oxford: Oxford University Press.

Carruthers, P. (2002). The Cognitive Functions of Language. Behavioral and Brain Sciences, 25, 657-726.

Carruthers, P. (2011). The Opacity of Mind: An Integrative Theory of Self-knowledge. New York: Oxford University Press.

Carruthers, P. (2014). On Central Cognition. Philosophical Studies, 170, 143-162

Carruthers, P. (forth.). The Causes and Contents of Inner Speech, in P. LanglandHassan \& A. Vicente (eds.). Inner Speech: nature, functions, and pathology. Oxford University Press.

Chomsky, N. (2016). What Kind of Creatures are We? Columbia University Press.

Camp, E. (2009). A Language of Baboon Thought? In R.Lurz, (ed.). Philosophy of Animal Minds. Cambridge University Press: 108-127.

Crane, T. (forth.). The Unity of Consciousness. Proceedings of the Aristotelian Society.

Dell, G. S. (1995). Speaking and misspeaking. In Gleitman, L. R. \& Liberman, M. (eds.). Language, vol. 1 of An Invitation to Cognitive Science, second edn., chap. 7, pp. 183-208. Cambridge, MA: MIT Press.

Engelbert, M. \& Carruthers, P. (2011). Descriptive Experience Sampling: What is it good for? Journal of Consciousness Studies 18:130-149.

Evans, N. \& Levinson, S. C. (2009). The myth of language universals: Language diversity and its importance for cognitive science. Behavioral and Brain Sciences 32:429-92.

Farkas, K. (2008). Phenomenal Intentionality Without Compromise, The Monist 91 (2): 273-93.

Feinberg, I. (1978). Efference Copy and Corollary Discharge: Implications for Thinking and its Disorders. Schizophrenia Bulletin 4: 636-640.

Frankish, K. (2004). Mind and Supermind. Cambridge University Press.

Frith, C. (1992). The Cognitive Neuropsychology of Schizophrenia. Hover: Lawrence Erlbaum Associates.

Frith C. (2012). Explaining delusions of control: the comparator model 20 years on. Consciousness and Cognition 21, 52-54.

Gambi, C. \& Pickering, M. (2016). Predicting and imagining language. Language; Cognition and Neuroscience, 31 (1), 60-72. 
Garrod, S., Gambi, C. \& Pickering, M. (2013). Prediction at all levels: forward model predictions can enhance comprehension. Language, Cognition and Neuroscience, 29:1, 46-48,

Gauker, C. (2011). Words and Images: An Essay on the Origin of Ideas. Oxford University Press.

Gauker, C. (forth.). Inner Speech as the Internalization of Outer Speech. in P. LanglandHassan \& A. Vicente (eds.). Inner Speech: nature, functions, and pathology. Oxford University Press.

Glock, H-J. (2000). Animals, Thoughts and Concepts. Synthese 123: 35-64.

Guillot, A., Di Rienzo, F., MacIntyre, T., Moran, A. \& Collet C. (2012). Imagining is not doing but involves specific motor commands: a review of experimental data related to motor inhibition. Frontiers in Human Neuroscience, 6:247.

Graham, G., Horgan, T., \& Tienson, J. (2007). Consciousness and Intentionality. In M. Velmans \& S. Schneider (eds.). The Blackwell Companion to Consciousness, Oxford: Blackwell, 468-484.

Hartsuiker, R. (2014). Monitoring and Control of the Production System. In M. Goldrick, V., Ferreira, \& M. Miozzo (eds.). The Oxford Handbook of Language Production. Oxford: Oxford University Press. 417-436

Helmholtz, H. V. (1860). Treatise on Physiological Optics. New York: Dover.

Horgan, T., \& Graham. G. (2012) Phenomenal Intentionality and Content Determinacy. In R. Shantz (ed.). Prospects for Meaning. Amsterdam: de Gruyter, 321-344.

Horgan, T, \& Tienson, J. (2002). The Intentionality of Phenomenology and the Phenomenology of Intentionality. In D. Chalmers (ed.). Philosophy of Mind: Classical and Contemporary Readings. Oxford: Oxford University Press, 520533.

Hespos, S. J. \& Spelke E. S. (2004). Conceptual precursors to spatial language. Nature 430:453-6.

Hickok, G. \& Poeppel, D. (2007). The cortical organization of speech processing. Nature Reviews Neuroscience 8: 393-402.

Hickok, G. (2012). Computational neuroanatomy of speech production. Nature Reviews Neuroscience, 13(2), 135-145.

Hurlburt, R.T. (2009). Unsymbolized Thinking, Sensory Awareness, and Mindreading. Behavioral and Brain Sciences, 32, 29-30.

Hurlburt, R.T. (2011). Investigating Inner Experience: Moments of Truth. Cambridge, MA: Cambridge University Press.

Hurlburt, R. T. \& Akhter, S. A. (2008). Unsymbolized Thinking. Consciousness and Cognition 17: 1364-1374.

Hurlburt, R. T. \& Heavey, Ch. L, (2006). Exploring Inner Experience. The descriptive experience sampling method. Amsterdam/Philadelphia: John Benjamins Publishing Company.

Hurlburt, R. T., Heavey, C. L. \& Kelsey, J. M. (2013). Toward a Phenomenology of Inner Speaking. Consciousness and Cognition, 22: 1477-1494.

Hurlburt, R. T., Alderson-Day, B., Fernyhough, C. P. \& Kühn, S. (2017). Can inner experience be apprehended in high fidelity? Examining brain activation and experience from multiple perspectives. Frontiers in Psychology, 8(43). doi: 10.3389/fpsyg.2017.00043

Hurlburt, R. T. \& Schwitzgebel, E. (2007). Describing Inner Experience? Proponent Meets Skeptic. Cambridge, MA: MIT Press.

Jackendoff, R. (1996). How Language Helps us Think. Pragmatics and Cognition 4, 135 . 
Jeannerod, M. (2006). Motor Cognition: What Actions Tell the Self. Oxford: Oxford University Press.

Jorba, M. (2016). Attitudinal Cognitive Phenomenology and the Horizon of Possibilities, in T. Breyer, and Ch. Gutland (eds.). Phenomenology of Thinking. Philosophical Investigations into the Character of Cognitive Experiences. London: Routledge: p. 77-96.

Jorba, M. \& Moran, D. (2016). Conscious Thinking and Cognitive Phenomenology: Topics, Views and Future Developments. Philosophical Exaplorations 19 (2): 95113.

Jorba, M. \& Vicente, A. (2014). Cognitive Phenomenology, Access to Contents, and Inner Speech. Journal of Consciousness Studies 21 (9-10): 74-99.

Klinger, E. \& Cox. W. M. (1987-1988). Dimensions of thought flow in everyday life. Imagination, Cognition and Personality 7: 105-128.

Kriegel, U. (2014) The Phenomenal Intentionality Research Program, In Kriegel (ed.). Phenomenal Intentionality. Oxford: Oxford University Press, 1-27.

Kriegel, U. (2015). The Varieties of Consciousness. Oxford: Oxford University Press.

Kühn, S., Fernyhough, C., Alderson-Day, B. \& Hurlburt, R. T. (2014). Inner Experience in the Scanner: Can High Fidelity Apprehensions of Inner Experience Be Integrated with fMRI?. Frontiers in Psychology 5: 1-8.

Levelt, W. (1989). Speaking. MIT Press.

Levine, J. (2011). On the Phenomenology of Thought, in Bayne, T. \& Montague, M. (eds.). Cognitive Phenomenology. Oxford and New York: Oxford University Press, 103-120.

Loar B. (2003). Phenomenal Intentionality as the Basis of Mental Content. In M. Hahn \& B. Ramberg (eds.). Reflections and Replies: Essays on the Philosophy of Tyler Burge. MIT Press, 229-258.

Lœvenbruck, H., Grandchamp, R.. Rapin, L., Nalborczyk, L., Dohen, M., Perrier, P., Baciu, M. \& Perrone-Bertolotti, M. (forth.). Inner language: An act it is to spur the mind's eye, ear, and tact, in P. Langland-Hassan \& A. Vicente (eds.). Inner Speech: nature, functions, and pathology. Oxford University Press.

Loewer, B. \& Rey, G. (1992). Meaning in Mind: Fodor and his Critics. Blackwell

Lupyan, G. (2012). Linguistically modulated perception and cognition: The labelfeedback hypothesis. Frontiers in Cognition 3. doi:10.3389/fpsyg.2012.00

Malt, B. C. \& Majid, A. (2013). How thought is mapped into words. WIREs Cognitive Science, 4, 583-597.

Martínez-Manrique, F \& Vicente, A. (2015) The activity view of inner speech, Frontiers in Psychology. 6:232. doi: 10.3389/fpsyg.2015.00232

Neander, K. (2012). 'Teleological Theories of Mental Content', The Stanford Encyclopedia of Philosophy (Spring 2012 Edition), Edward N. Zalta (ed.). URL = http://plato.stanford.edu/archives/spr2012/entries/content-teleological/

Noteboom, S. G. \& Quené, H. (2017). Journal of Memory and Language, 95: 19-35.

Oppenheim G. M. (2013). Inner speech as a forward model? Behavioral and Brain Sciences 36, 369-370.

Pautz, A. (2014). Does Phenomenology Ground Mental Content? In Kriegel (ed.). Phenomenal Intentionality. Oxford: Oxford University Press, 194-234.

Pacherie, E. (2008). The Phenomenology of Action: a Conceptual Framework. Cognition 107, 179-217.

Perrone-Bertolotti, M., Rapin, L., Lachaux, J.-P., Baciu, M., \& Lœven-bruck, H. (2014). What is that little voice inside my head? Inner speech phenomenology, its role in 
cognitive performance, and its relation to self-monitoring. Behavioural Brain Research, 261, 220-239.

Pickering, M. \& Garrod, S. (2013). An integrated theory of language production and comprehension. Behavioral and Brain Sciences 36, 329-347.

Pitt, D. (2004). The Phenomenology of Cognition or What Is It Like To Think That P?, Philosophy and Phenomenological Research, 69: 1-36.

Pitt, D. (2009). Intentional Psychologism, Philosophical Studies, 146: 117 - 138.

Pitt, D. (manuscript). Unconscious Intentionality.

Prinz, J. (2011). The Sensory Basis of Cognitive Phenomenology, in Bayne, T. \& Montague, M. (eds.). (2011). Cognitive Phenomenology. Oxford: Oxford University Press. 174-196.

Rapin, L., Dohen, M., Polosan, M., Perrier, P. \& Loevenbruck, H. (2013). An EMG study of the lip muscles during covert auditory verbal hallucinations in schizophrenia. Journal of Speech, Language, and Hearing Research 56:1882-93.

Regier, T. \& Kay, P. (2009). Language, thought, and color: Whorf was half right. Trends in Cognitive Sciences 13: 439-4

Samoilova, K. (2016). Transparency and Introspective Unification, Synthese, 193: 3363-3381.

Siewert, Ch. (1998). The Significance of Consciousness. Princeton, NJ: Princeton University Press.

Spelke, E. S. (2003). What Makes Us Smart? Core Knowledge and Natural Language. In D. Gentner \& S. Goldin-Meadow (eds). Language in Mind. Cambridge, MA: MIT Press, 277-311.

Sperry, R. W. (1950). Neural Basis of the Spontaneous Optokinetic Response Produced by Visual Inversion. Journal of Comparative and Physiological Psychology 43: $482-489$.

Strawson, G. (2008). Real Intentionality: Why Intentionality Entails Consciousness. In Strawson, G. Real Materialism and Other Essays. Oxford: Oxford University Pres. 381-305

Strawson, G. (2010). Mental Reality (2nd edition). Cambridge, London: MIT Press.

Swiney, L. \& Sousa P. (2014). A New Comparator Account of Auditory Verbal Hallucination: How Motor Prediction Can Plausibly Contribute to the Sense of Agency for Inner Speech. Frontiers in Human Neuroscience 8: 675.

Tye, M. \& Wright, B. (2011). Is there a phenomenology of thought?, in M. Bayne, T. \& Montague, M. (eds.). Cognitive Phenomenology. Oxford and New York: Oxford University Press, 326-344.

Vicente, A. (2014). The comparator account on thought insertion, alien voices and inner speech: some open questions. Phenomenology and the Cognitive Sciences 13: 335-353.

Vicente, A., \& Martínez-Manrique, F. (2008). Thought, Language, and the Argument from Explicitness. Metaphilosophy, 39(3): 381-401.

Vicente, A \& Martínez-Manrique, F. (2016). The nature of unsymbolized thinking. Philosophical Explorations, 19 (2), 173-187.

von Holst, E. \& Mittelstaedt, H. (1950). 'Das Reafferenzprinzip.' Die Naturwissenschaften 20: 464-476.

Wilson, R. (2003). Intentionality and Phenomenology, Pacific Philosophical Quarterly 84: 413-431. 